\title{
Case Report: Intracardiac Mass, the Importance of Early Diagnosis and Surgical Intervention
}

\author{
Samir Rafla1 ${ }^{(0)}$, Tarek Bishay ${ }^{2}(\mathbb{C}$ \\ ${ }^{1}$ Emeritus Professor of Cardiology Department, Alexandria University, Alexandria, Egypt \\ ${ }^{2}$ Cardiology Department, National Heart Institute, Cairo, Egypt \\ Email:smrafla@yahoo.com, Tarek_a_bishay@yahoo.com
}

How to cite this paper: Rafla, $\mathrm{S}$. and $\mathrm{Bi}$ shay, T. (2021) Case Report: Intracardiac Mass, the Importance of Early Diagnosis and Surgical Intervention. Case Reports in Clinical Medicine, 10, 240-245. https://doi.org/10.4236/crcm.2021.109031

Received: July 24, 2021

Accepted: September 11, 2021

Published: September 14, 2021

Copyright (c) 2021 by author(s) and Scientific Research Publishing Inc. This work is licensed under the Creative Commons Attribution International License (CC BY 4.0).

http://creativecommons.org/licenses/by/4.0/ cc (i) Open Access

\begin{abstract}
Background: Cardiac masses are not rare findings; they can be primary or secondary. The differential diagnosis may need surgical intervention in most cases. Case summary: A 42-year female presented with complaints of dyspnea, palpitations, ventricular premature beats, attacks of non-sustained ventricular tachycardia. Echocardiography revealed a myocardial septal mass on both sides in the right and left ventricles. The decision to operate was taken and the masses were removed. It was proved by histopathologic examination to be metastatic from her skin melanoma. Clinically, arrhythmias subsided. Conclusion: The decision of surgery proved unavoidable. Early diagnosis by surgical intervention is important for effective treatment.
\end{abstract}

\section{Keywords}

Melanoma, Case Report, Cardiac Masses, Echocardiography, Surgical Intervention

\section{Introduction}

Cardiac metastases occasionally complicate the course of neoplastic diseases. Malignant melanoma is a known neoplasm that frequently involves the heart [1].

Non-specific clinical signs of cardiac involvement should be thought off and shouldn't be masked by other manifestations of the tumor [2]

Metastatic melanoma is usually refractory to chemotherapy, and has a poor prognosis, especially with cardiac involvement.

\section{Case}

Female patient, Caucasian, 42 years old. Not obese. Not known to be diabetic, hypertensive, ischemic, or with rheumatic heart disease. Has chronic obstructive 
pulmonary disease (COPD). Her complaint was palpitations and dyspnea (from her COPD). No family history of malignancy, as much as she can remember.

Pulse: 120/min. BP 110/70. Auscultation: unremarkable. Electrocardiogram (ECG): sinus tachycardia, VPBs (ventricular premature beats). Holter monitor: revealed frequent multifocal VPBs, attacks of nonsustained ventricular tachycardia (VT). She was referred for Echocardiography transthoracic (TTE) and transesophageal (TEE) (Figures 1-4). PET scanning was not done. Magnetic resonance imaging (MRI) was not done.

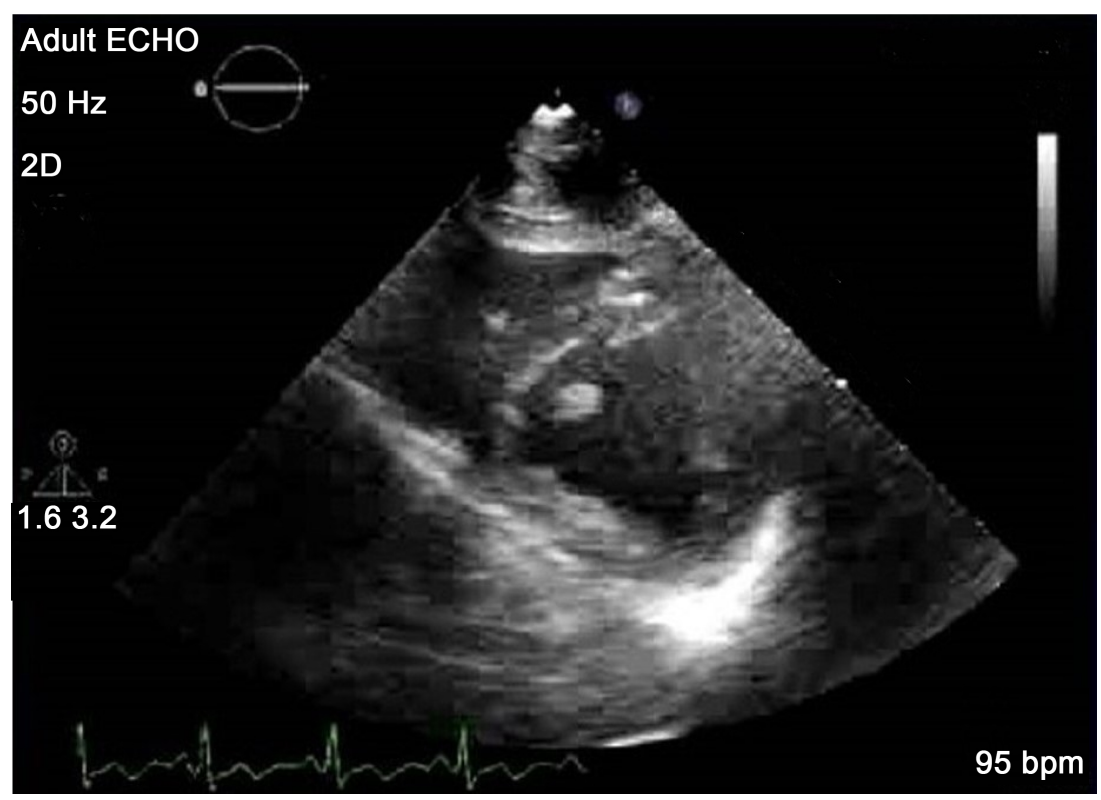

Figure 1. 2DE, TTE, short-axis view, showing 2 masses attached to both sides of the interventricular septum. The words in the figures are Adult Echo, $\mathrm{Hz}$ number, beat per minute (bpm).

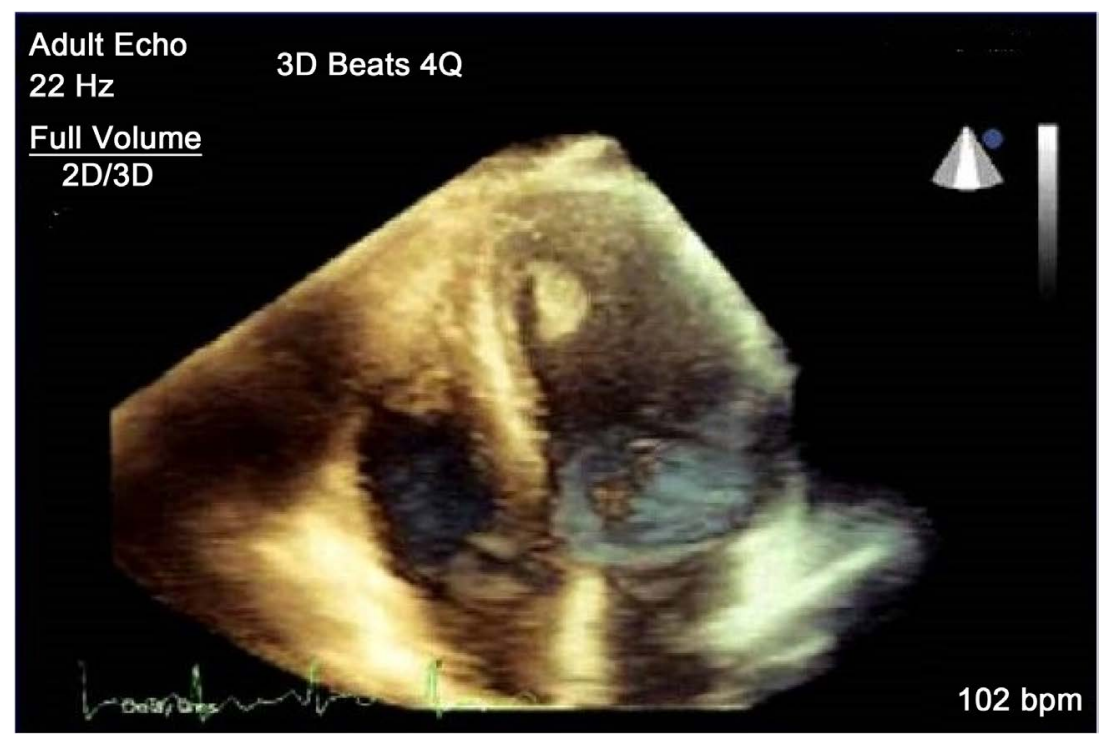

Figure 2. 3DE, TTE, 4 chamber view, showing 2 masses at the apical part of the LV and RV. 


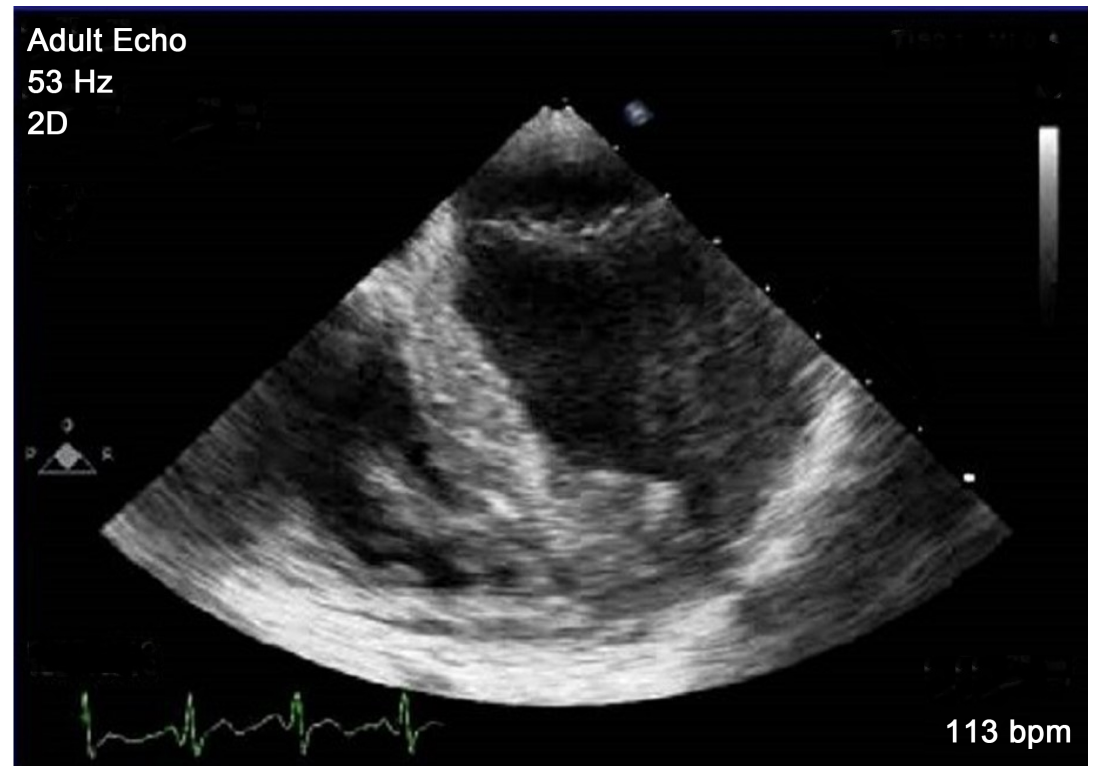

Figure 3. DE, TEE, 4 chamber view, showing 2 masses attached to both sides of the interventricular septum.

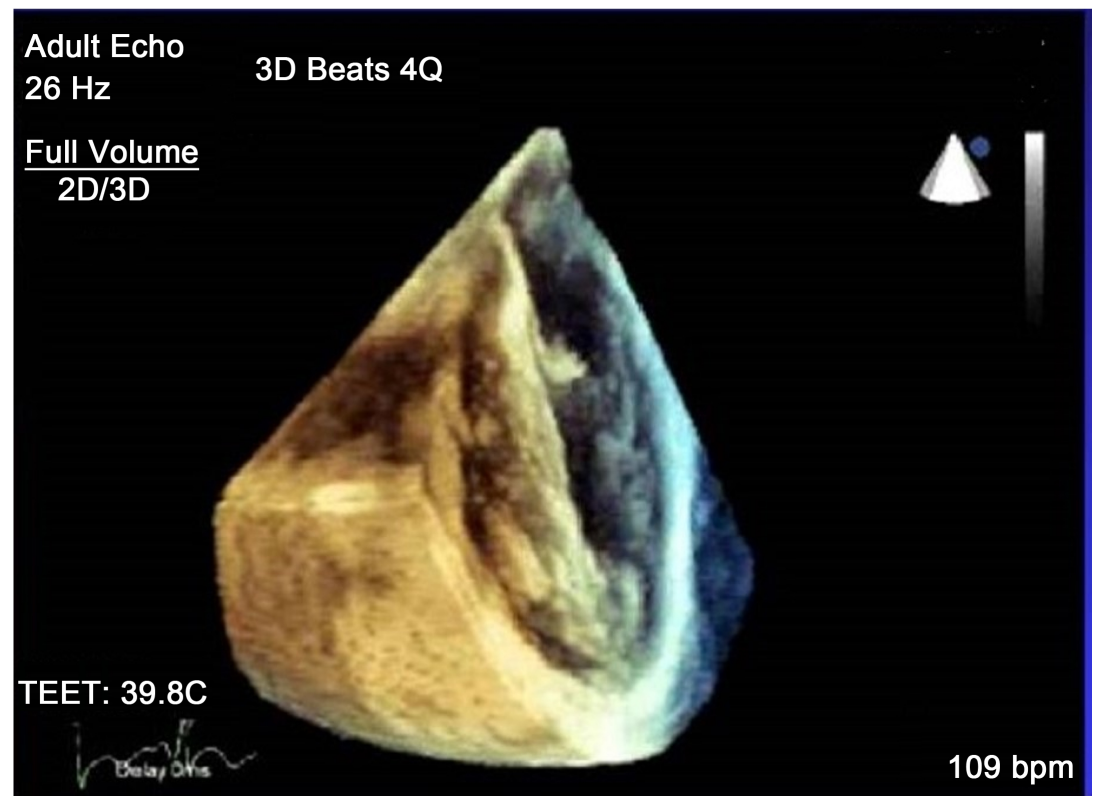

Figure 4. 3DE, TEE, 4 chamber view, showing 2 masses attached to both sides of the interventricular.

Echocardiography findings:

A mass is attached to the septum near the apex, inside the left ventricle, and extends to the RV side of the septum. No calcification, solid i.e., no vacuoles or cavities, sessile not pedunculated.

The site of the melanoma was at the skin of her back. At the Oncology hospital, they diagnosed it. There were no other metastases in her body.

A consultation committee was done to decide what to do for her (consultants in Oncology, Cardiology, and Cardiac Surgery). The oncologists did not agree 
with the suggestion of doing an Echo-guided biopsy by catheter as the oncologists considered the procedure to be dangerous and is not without high risk. Their opinion was that when the diagnosis is possible and therapeutic cardiac surgical intervention is warranted, it would be reasonable to force directly to cardiac surgery without a confirmatory tissue diagnosis. Finally, the committee requested for her to do MRI with tissue characterization. However, because it was not available at the hospital at that time, she was scheduled to do it in another hospital. Unfortunately, her symptoms deteriorated, her dyspnea and palpitations increased too much (she had COPD). The committee met again and decided on her urgent cardiac surgery.

She was referred to the Oncology Institute to evaluate her for any malignancies. Their diagnosis was Malignant Melanoma (MM) found in the skin of her back with no metastases to the other organs. The skin melanoma was excised and analyzed by histopathology also. They started treatment for her.

Surgery was done (4 days from the first date of admission), excision of the 2 masses in the RV and LV was done. They found that both of them were attached to the distal part of the interventricular septum on both sides with the mass in the LV attached to it slightly lower than the RV mass. Echocardiography is shown in Figures 1-4.

Histological diagnosis was metastatic malignant melanoma.

Histopathology: The mass was confirmed to be malignant melanoma histopathologically. Tumor cells were mostly round and epithelioid in morphology with hyperchromatic nuclei.

After surgery, her symptoms improved dramatically, also no arrhythmias were detected. Then she was referred to the Oncology Institute to treat the MM. We do not have a copy of the histology slides.

\section{Discussion}

MM has the highest rate of intracardiac metastases of any tumor, involving it in more than $50 \%$ in old series [1] [2]. In the reported autopsy series of MM, Glancy et al. found intracardiac metastases in 45 of 70 patients (64\%) dying of metastatic melanoma. Other researchers report frequencies up to $71 \%$. The location of involvement of metastatic diseases is frequently the pericardium, resulting in pericardial effusion and epicardial involvement (from breast or lung cancer).

Intramyocardial involvement is less common than pericardial metastases and occurs secondary to MM and a much lesser percentage by lymphoma. Reports describing intracardiac metastases from MM make most of the published cases, many of these having been incidental findings in the course of investigation for other indications (Table 1).

So, intracardiac metastases are frequently seen as a manifestation of MM. Electrocardiogram (ECG) findings were typically nonspecific, occurred late, and were unrelated to disease extent. 
Table 1. Metastatic tumors to the heart source and cardiac manifestations.

\begin{tabular}{cc}
\hline Original Source & Cardiac Effect \\
\hline Breast & Hematogenous or lymphatic spread; effusion common \\
Melanoma & Intracardiac or myocardial involvement \\
Renal cell carcinoma & IVC to RA to RV; confused with thrombus \\
Carcinoid & Tricuspid and pulmonic valve thickening \\
\hline
\end{tabular}

Sudden Cardiac Death (SCD), arrhythmias, HF, pulmonary embolism (PE), and obstruction to flow can develop as a result of intramyocardial metastatic melanoma.

Unfortunately, there is a poor correlation between clinical features, ECG changes, and objective evidence of cardiac metastases [3]-[10].

Wood et al. [11] reported about seven patients with intracardiac mass proved to be metastatic melanoma. All patients presented with dyspnea. Echocardiography or CT revealed an intracardiac mass (four atrial, three ventricular). History of malignant melanoma was known in five of the seven patients. The other two had a melanoma removed years ago.

Reports of intracavitary metastases from malignant melanoma constitute the majority of the reported cases, many have been an incidental finding in the course of investigation [9] [10].

Management: If MM has already spread to the heart, these metastases should be removed immediately, if possible, because of its very rapid rate of growth up to occupying the whole heart, and also rapid spread beside it can lead to SCD. Swetter et al. published an important paper on guidelines of care for the management of primary cutaneous melanoma [12].

So, surgical removal of intramyocardial metastatic melanoma should be considered as first-line therapy.

\section{Conclusions}

Neoplastic involvement of the heart should be thought of in patients with cardiac symptoms when a documented malignancy exists, even in remote area.

TEE allows the detection of small metastases, their definite location, and their shape and size exactly; so, it should be done to them. In patients with cardiac metastatic melanoma, cardiac surgery should be done if there is no contraindication.

\section{Acknowledgements}

The authors are grateful to all the staff who helped in echocardiography or surgery in the two hospitals.

\section{Conflicts of Interest}

None. 


\section{References}

[1] Klatt, E.C. and Heitz, D.R. (1990) Cardiac Metastases. Cancer, 65, 1456-1459. https://doi.org/10.1002/1097-0142(19900315)65:6\%3C1456::AID-CNCR2820650634 \%3E3.0.CO;2-5

[2] Glancy, D.L. and Roberts, W.C. (1968) The Heart in Malignant Melanoma: A Study of 70 Autopsy Cases. American Journal of Cardiology, 21, 555-571. https://doi.org/10.1016/0002-9149(68)90289-0

[3] Qu, G.Z., Kaur, J.S. and Seward, J.B. (2003) Metastatic Melanoma Presenting as Cardiac Mass and Hemobillia. The American Journal of the Medical Sciences, 325, 157-159. https://doi.org/10.1097/00000441-200303000-00009

[4] Waller, B.F., Gottdiener, J.S., Virmani, R. and Roberts, W.C. (1980) The Charcoal Heart: Melanoma to the Core. Chest, 77, 671-676.

https://doi.org/10.1378/chest.77.5.671

[5] Matturri, L., Nappo, A., Varesi, C. and Rossi, L. (1993) Cardiac Metastasis of Malignant Melanoma. Pathologica, 85, 97-102.

[6] Malouf, J.F., Thompson, R.C., Maples, W.J. and Wolfe, J.T. (1996) Diagnosis of Right Atrial Metastatic Melanoma by Transesophageal Echocardiographic-Guided Transvenous Biopsy. Mayo Clinic Proceedings, 71, 1167-1170. https://doi.org/10.4065/71.12.1167

[7] Sheldon, R. and Isaac, D. (1991) Metastatic Melanoma to the Heart Presenting with Ventricular Tachycardia. Chest, 99, 1296-1298. https://doi.org/10.1378/chest.99.5.1296

[8] Gibbs, P., Cebo, S.J., Calafiore, P. and Robinson, A.W. (1999) Cardiac Metastases from Malignant Melanoma. Cancer, 85, 78-84. https://doi.org/10.1002/(SICI)1097-0142(19990101)85:1\%3C78::AID-CNCR11\%3E3 $.0 . \mathrm{CO} ; 2-5$

[9] Savoia, P., Fierro, T.M., Zaccagna, A. and Bernengo, G.M. (2000) Metastatic Melanoma of the Heart. Journal of Surgical Oncology, 75, 203-207. https://doi.org/10.1002/1096-9098(200011)75:3\%3C203::AID-JSO9\%3E3.0.CO;2-X

[10] Ozyuncu, S.N., Altin, T. and Karaoguz, R. (2006) Cause of Complete Atrioventricular Block. EP Europace, 8, 545-548. https://doi.org/10.1093/europace/eul058

[11] Wood, A., Markovic, S.N., Best, B.J.M. and Erickson, L.A. (2010) Metastatic Malignant Melanoma Manifesting as an Intracardiac Mass. Cardiovascular Pathology, 19, 153-157. https://doi.org/10.1016/j.carpath.2008.12.010

[12] Swetter, S.M., Tsao, H., Bichakjian, C.K., Curiel-Lewandrowski, C., Elder, D.E., Gershenwald, J.E., et al. (2019) Guidelines of Care for the Management of Primary Cutaneous Melanoma. Journal of the American Academy of Dermatology, 80, 208-250. https://doi.org/10.1016/j.jaad.2018.08.055 